\title{
The Leading Cancer Types in Afghanistan
}

\author{
Ahmad Javid Safi \\ Department of Medical Oncology, China Medical University, Shenyang, China \\ Email:pracf155@gmail.com
}

How to cite this paper: Safi, A.J. (2019) The Leading Cancer Types in Afghanistan. Journal of Cancer Therapy, 10, 877-881. https://doi.org/10.4236/jct.2019.1011074

Received: August 26, 2019

Accepted: October 22, 2019

Published: October 25, 2019

Copyright (c) 2019 by author(s) and Scientific Research Publishing Inc. This work is licensed under the Creative Commons Attribution International License (CC BY 4.0).

http://creativecommons.org/licenses/by/4.0/

\begin{abstract}
Background: Researches have shown that cancer is one of the chief causes of death in most of the advanced and developed countries; and in the developing countries, cancer is the second leading cause of death. In Afghanistan, approximately twenty-thousand $(20,000)$ people are diagnosed with cancer annually and fifteen-thousand among these patients die in the same year. Breast cancer in the women is reported to be the highest, stomach the second and blood cancer in the third category in Afghanistan. Method: A questionnaire-based survey during the public awareness campaigns in schools, universities and other public places was conducted by Afghanistan Cancer Foundation in 2018. In the campaigns, the participants were asked to fill the questionnaire; after their consent, the participants returned the questionnaires were analyzed by Afghanistan Cancer Foundation. Results: The survey was conducted over a total population of 238,491 including 121,192 females and 117,299 males. Death cases were reported to be 8335 while the total number of alive patients reaches up to 368. Furthermore, 121 cases of Breast, 64 of stomach, 50 of Leukemia, 19 of Liver, 11 of Esophagus, 9 of Cervix \& Uterine, 9 of Brain and 85 cases of other types of cancer were reported. Conclusion: Breast, stomach and blood cancers are the frequently diagnosed cancer sites in Kabul.
\end{abstract}

\section{Keywords}

Breast, Stomach and Blood Cancers

\section{Introduction}

A landlocked and mountainous country located within South Asia and Central Asia, Afghanistan is bordering China, Pakistan, Iran, Turkmenistan, Uzbekistan and Tajikistan. Apart from the physical connection with these countries, there lies a deep ethnic connection between Afghanistan and the before mentioned countries [1]. A country with an estimated population about 32.5 million, Afg- 
hanistan is ranked 41st most populous nation around the globe. The middle age of Afghans is 18.4 years, which shows high growth rate of the population that is $2.32 \%$. Similarly, studies show a high birth rate of $38.57 / 1000$ population, and death rate of 13.89 deaths/100,000 population. Altogether these factors contribute to a low life expectancy rate of 51 years. The gross domestic product on health care spent in Afghanistan is nearly 8.5\%, which does not explain to actual welfares. The density of physicians is 0.27 physicians/ 1000 population and the density of hospital beds is 0.5 beds/ 1000 population which shows clear contrast to the statistics of that in the US. In the United States, the density of physicians is $2.45 / 1000$ people and beds $2.9 / 1000$ people [2].

The ethnic aspects of this country have deep-rooted association with diseases like cancer. In the late 1960s, Department of Pathology established a Tumor Registry Department for non-communicable diseases in Kabul University, now known as Kabul Medical University [3]. The first research that lasted for two and half years, reveals the frequencies of benign and malignant neoplasms collected on the basis of survey of the Registry. Civil war and social disturbances in the country disturbed almost everything and, therefore, no further research took place in the field of non-communicable diseases in Afghanistan. Since then, very few researches and cancer-related data are available in Afghanistan. The findings of Tumor Registry Department show that in the late 60s that the major sites of cancer in Afghans were skin, lymphoid and hematopoietic systems, soft tissues, eye, breast and testis. Other than these, cancers of stomach, the esophagus and the ovary were the most frequently diagnosed sites [4]. Other cancers like mouth cancer and uterine cervix were of relatively low frequency. Since that, this is the basic and important finding that exposes certain conditions that exist in the country associated with tumours. Recently WHO discovered cancer statistics which shows a great deal of contrast with earlier statistics of cancer in Afghanistan. According to World Health Organization report, approximately 20,000 Afghans were diagnosed with cancer in 2014. Most of the cancers cases that were diagnosed were breast, cervix, stomach, esophagus, lung and head \& neck cancers [5]. The report reveals that approximately 15,000 Afghans died of cancer. These data represent the lack of primary screening of all sites. Based on cases reported, the mortality rate among Afghan women from breast cancer places it among the highest in the world. Breast cancer incidence rose by approximately 47\% during 2000-2012. In the developed-world, the 5-year survival rate for breast cancer is c.a. $90 \%$ for all stages, and $99 \%$ for localized disease at diagnosis. Due to the lack of timely diagnosis and inadequate treatment, women are disproportionately dying from this disease in Afghanistan. However, significant efforts are put to work recently by the different institutions, organizations and health departments to increase awareness of cancer risks, signs, symptoms and prevention measures. The most effective efforts to-date are the increase in the level of education on self-breast exams of the public [6].

Moreover, Shukat Khanum Hospital, a cancer diagnostic and treatment center in Pakistan, revealed the annual facts and figures of cancer patients from Afgha- 
nistan to the above mentioned hospital for treatment. The diagnosis shows different sites of cancer. The report depicts the major sites of cancer diagnosed in Afghans. A total number of 567 patients are treated on 2016 the mentioned hospital the statistics of which is as, Esophagus 183 with $24.6 \%$, Stomach 116 with $15.6 \%$, Breast 60 with $8.1 \%$, Leukaemia 49 with $6.6 \%$, Colon/Rectum 42 with $5.6 \%$, Hodgkin's Lymphoma 30 with $4.0 \%$, Non-Hodgkin's Lymphoma 26 with $3.5 \%$, Skin 24 with $3.2 \%$, Testis 19 with $2.6 \%$ and Prostate 18 with $2.4 \%$ [7].

\section{Cancer Burden in Afghanistan}

Suffering from civil war, Afghanistan loses a huge number of its population due to cancer which much higher than the rates of the loss of live in the war annually. Cancer is huge burden on the shoulders of the government which needs a perpetual and passionate fight to reduce the cancer incidents in Afghanistan. The main cause of the unavailability of integrated cancer prevention in Afghanistan is the lack of public awareness among the commoners. The masses have no or very little knowledge about the preventive measures of cancer which contributes to the high rates of cancer incidents in Afghanistan. The deficiency of cancer policy and the lack of robust cancer registries on national level is another factor that lets the cancer threat increase. At the public primary health-care level, the screening for early detection of breast, cervical, and colorectal and other cancers is not normally accessible. Moreover, there is no standard radiotherapy or chemotherapy and other treatments existing in Afghanistan for which the patients are obliged to travel for these services to the neighbouring countries. Even though in the past, there existed some facilities, a cancer treatment center in the late $60 \mathrm{~s}$ in Ali Abad Hospital Kabul, but the warfare and unfortunate four decades demolished the maximum facilities of cancer treatment. In 2016, a cancer foundation, Afghanistan Cancer Foundation, was founded to revive the awareness about cancer and pave the ground for the future cancer treatment in Afghanistan. The idea of the foundation was inspired by the female cancer survivors and then some of the influential women supported the idea; as a result, Afghanistan Cancer Foundation came into being by their struggle which presently working to reduce cancer incidents in Afghanistan. The foundation attracted the attention of the government to focus on the cancer treatment; initially, a cancer ward is established in Jamhoriat Hospital in Kabul City the services provided in this center are almost negligible to reduce cancer incidents in the country. It is partly because of the nonexistence of the oncologists and partly because of the cancer treatment technology. Recently International Atomic Energy Agency is moved for the re-establishment of the radiotherapy for cancer treatment facility formerly located in Ali Abad Hospital.

Moreover, during the illness, patients need quality palliative care in cancer; patients suffer from strong physical pain which makes the patients weak. The pain is felt chiefly when the disease reaches to its later and advanced stages. Cancer patients in Afghanistan are at stake because there are no standard palliative care services available. 
Cancer is a major threat to adults, children and aged people in Afghanistan. The lack of awareness about cancer makes the situations even worst. A cancer research is as important as public awareness simultaneously. A cancer foundation, Afghanistan Cancer Foundation, is currently working on a cancer registry. This registry will play a vital role in the cancer registry of Afghanistan and will be a great advantage for comprehensive researches in the future.

\section{Method}

A survey, based on questionnaire, was conducted by Afghanistan Cancer Foundation in Kabul city in 2018. In the survey, an approximately of 238,491 people participated. The population of the survey was including both males and females among which were 121,192 females and 117,299 males. The data were collected on the basis of gender, death/alive and types of cancer. The data were collected from schools, universities and other public areas during cancer public awareness campaigns in Kabul city.

\section{Result}

The result of the survey was conducted in Kabul city. The survey was conducted over a total population of 238,491 which includes 121,192 females which form $50.8 \%$ and 117,299 which forms $49.2 \%$ of the population. In the population that was taken for the survey, 8335 were the total death cases which form $3.49 \%$ and a total number of 368 alive patients form $0.15 \%$ of the population.

The data show that there are 368 cancer cases that are alive. In these cases, 121 cases belong to Breast, 64 to stomach, 50 to Leukemia, 19 to Liver, 11 to Esophagus, 9 to Cervix \& Uterine, 9 to Brain 85 to other types of cancer. Furthermore, patients of breast cancer forms 33\%, stomach $17 \%$, blood cancer $14 \%$, liver 5\%, Esophagus 2.9\%, Cervix \& Uterine 2.4\%, Brain $2.4 \%$ and others $23 \%$ of the patients.

\section{Conclusion}

In a conclusion, breast cancer is recorded to be the highest occurring cancer in Afghan women comparatively to the developed countries, particularly in Kabul city. The main reason of the breast cancer high frequency is the low or no basic education and awareness about self-breast examination in the women. Furthermore, stomach cancer is the second in number, frequently occurring cancer, in Afghans, specifically in men. The level of public awareness is too low about the risk factors and nonexistence of treatment facilities of the stomach cancer in Afghanistan, therefore, it is the second leading cancer diagnosed in Afghanistan. And finally, blood cancer is the third frequently occurring cancer in Afghan society.

\section{Conflicts of Interest}

The author declares no conflicts of interest regarding the publication of this paper. 


\section{References}

[1] Siegel, R.L., Miller, K.D. and Jemal, A. (2018) Cancer Statistics. CA: A Cancer Journal for Clinicians, 68, 7-30. https://doi.org/10.3322/caac.21442

[2] Are, C. (2016) Cancer on the Global Stage: Incidence and Cancer-Related Mortality in Afghanistan.

http://www.ascopost.com/issues/january-25-2016/cancer-on-the-global-stage-incide nce-and-cancer-related-mortality-in-afghanistan/

[3] Mohammad, H.H., Mohammad, H.S., Kanda, M., Sakamoto, J., Hamrah, M.H., Hami, A. and Hamrah, M.H. (2017) Esophageal Cancer and Associated Factors among Uzbek-Turkmen and Other Ethnic Groups in the Northern Part of Afghanistan. Asian Pacific Journal of Cancer Prevention, 18, 333-337.

[4] Sobin, L.H. (1969) Cancer in Afghanistan. Cancer, 23, 678-688. https://doi.org/10.1002/1097-0142(196903)23:3<678::AID-CNCR2820230322>3.0.C $\underline{\mathrm{O} ; 2-4}$

[5] WHO (2014) Cancer Country Profiles: Afghansitan.

[6] Jemal, A., Bray, F., Center, M.M., Jacques, F., Ward, E. and Forman, D. (2011) Global Cancer Statistics. CA: A Cancer Journal for Clinicians, 61, 69-90. https://doi.org/10.3322/caac.20107

[7] Shaukat Khanam Cancer Center (2016) Afghans Traveling to Shaukat Khanum for Cancer Care. 